\title{
Modeling of Water Flow in Reclaimed Mine Spoil with Embedded Lignitic Fragments Using Hydrus-1D
}

\author{
Cong-an Ma $\cdot$ Qing-xiang Cai $\cdot$ Hui Wang $\cdot$ \\ Ming'an Shao · Jun Fan · Zhuye Shi • \\ Fengxi Wang
}

Received: 31 December 2013/Accepted: 15 July 2014/Published online: 21 August 2014

(C) The Author(s) 2014. This article is published with open access at Springerlink.com

\begin{abstract}
Lignitic mine soils represent a dual-porosity medium consisting of a technogenic mixture of overburden sediments that include porous fragments embedded within a mostly coarse-textured matrix. Flow and transport process in such soils are not sufficiently understood. The objective of this study was to identify the most appropriate conceptual model for describing small-scale heterogeneity effects on flow based on the physical structure of the system. HYDRUS-1D was used to simulate water flow under field conditions. We compared a dual-porosity (mobileimmobile) model simulation of the field soil water with field monitoring results. The predicted and observed water content were in good agreement. Since the heterogeneity of the lignitic mine soil may lead to preferential flow, Coomassie brilliant blue dyes were applied to the reclaimed surface, revealing preferred flow paths through macropores surrounding the numerous, large rock fragments.
\end{abstract}

Keywords Dual-porosity $\cdot$ Mobile-immobile $\cdot$ Spatial heterogeneity - Hydrus-1D - Preferential flow - Coal mine waste $\cdot$ Vadose zone

C. Ma $(\bowtie) \cdot$ Q. Cai $\cdot$ F. Wang

School of Mines, China University of Mining and Technology (CUMT), Xuzhou 221116, Jiangsu, People's Republic of China e-mail: zw1766@sina.com; macongan8@sina.com

H. Wang

School of Environment Science and Spatial Informatics, CUMT, Xuzhou 221116, Jiangsu, People's Republic of China

M. Shao $\cdot$ J. Fan $\cdot$ Z. Shi

Institute of Soil and Water Conservation, Chinese Academy of Sciences and Ministry of Water Resources,

Yangling 712100, Shaanxi, People's Republic of China

\section{Introduction}

In opencast mining, overburden sediments are first removed from the coal seams using, for instance, dragline excavators. This destroys the original sediment layers; the sediments are then transported to a site where they are dumped, thereby creating large initially unsaturated spoil heaps. At our study sites, the resultant mine soil is a mixture of predominately sandy, overburden sediment with lignitic fragments of various geometries and sizes. The fragments are highly porous, so the mine soil represents a dual-porosity sandy soil system.

Despite a number of experimental (Gerke et al. 2001b; Hangen et al. 2004, 2005) and modeling attempts (Buczko and Gerke 2005, 2006; Buczko et al. 2001; Gerke et al. 1998, 2001a), flow and transport in heterogeneous mine soils is not well understood. In contrast to naturally developed soils, a finger-type preferential flow process (Hangen et al. 2004) seems to result from several interacting and temporally varying causes. Among these are the effects of the lignitic fragments, funneling along inclined structures, and finger-type flow regions influenced by spatially and temporally changing water repellence (Gerke 2006a, b; Gerke et al. 2001b).

Classically, water flow through variably-saturated soils is described by Richards' equation with a uniform flow domain (Simunek and van Genuchten 2008). Recently, efforts have been made at simulating contaminant transport under the influence of preferential flow using dual-porosity models (Gerke and van Genuchten 1993, 1996; Jarvis 2007; Simunek and van Genuchten 2008; Simunek et al. 2001, 2003). These dual-porosity models assume the coexistence of two separate pore domains: fractures (or inter-aggregate pores, cracks, and macro-pores); and matrix pores, with water exchange between the two 
domains. The two-domain concept, assuming either mobile-mobile or dual-porosity model flow domains, i.e. a mobile-immobile model (MIM), has mostly been used to describe flow and solute transport in aggregated or otherwise structured soils under variably saturated conditions. Our objective in this paper was to use HYDRUS-1D as a tool to understand the effect of preferential flow on water flow in mine soil containing porous, lignitic components. For the analysis of water movement, we compared 1D dual-domain (i.e. MIM) approaches with field monitoring data. We focused on conceptually understanding and describing the flow processes rather than on parameter optimization or stochastic model analysis.

\section{Materials and Methods}

\section{Soil Site Description and Experimental Data}

The mine soil samples were from the reclaimed Shenshan mine soil heap $\left(39^{\circ} 45^{\prime} \mathrm{N}, 110^{\circ} 11^{\prime} \mathrm{E} ; 1,476 \mathrm{~m}\right.$ above sea level), which is located approximately $23 \mathrm{~km}$ west of the city of Ordos (Inner Mongolia, China). The soil heap was created in 2009 by removing quaternary overburden sediments from nearby opencast lignite mines. The annual mean temperature is $8.7^{\circ} \mathrm{C}$ and average annual precipitation rate is $357 \mathrm{~mm}$.A $1 \mathrm{~m}$ deep and $2 \mathrm{~m}$ long trench was excavated for experiments and soil sampling at a location where quaternary sediments dominate. The soil profile had a clearly separate top soil and subsoil. The sandy tertiary sediments contained differing amounts of lignitic fragments. Large fragments can be identified as dark spots in Fig. 1. Volumetric water content was measured with time domain reflectometry (TDR). Fourteen TDR probes were installed along the trench at four locations spaced $50 \mathrm{~cm}$ apart laterally, at seven depths of $5,15,25,40,50$, and $60 \mathrm{~cm}$.

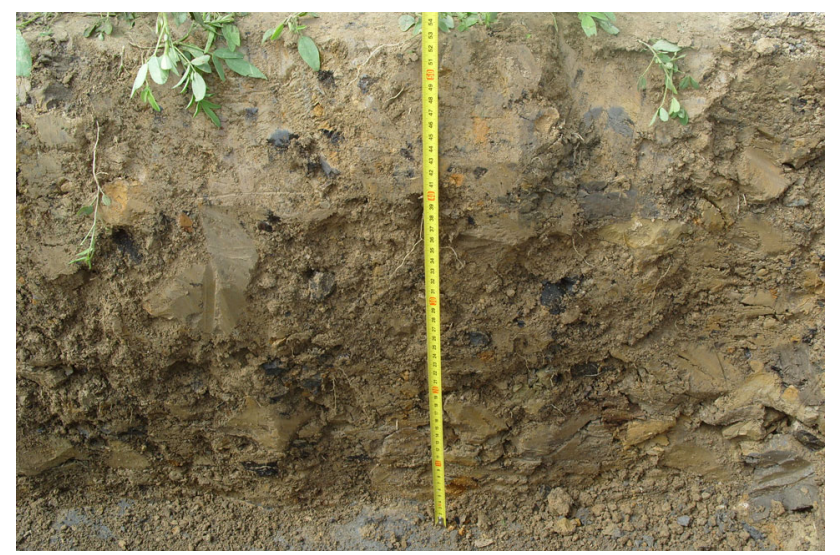

Fig. 1 Photographs of the $0.55 \mathrm{~m}$ vertical lignitic mine soil profile, about $0.9 \mathrm{~m}$ in width
Rainfall was measured and recorded continuously near the trench across a catchment area of $200 \mathrm{~cm}^{2}$. The trench was filled after all devices were installed. Field measurements started on 3 Aug 2012. We used 48 days of data.

\section{Flow Modeling}

To consider the significant effect of preferential flow on the mine soil with embedded lignitic components, a dualporosity flow model (based on mass transfer driven by differences in soil water pressure head) was selected from HYDRUS-1D. The dual-porosity formulation for water flow is based on a mixed formulation of the Richards equation to describe water flow in the macropores (mobile water region) and a mass balance equation to describe moisture dynamics in the matrix (immobile water region), as follows (Simunek et al. 2003):

$\frac{\partial \theta_{m}}{\partial t}=\frac{\partial}{\partial z}\left[K(h)\left(\frac{\partial h}{\partial z}+1\right)\right]-S_{m}-\Gamma_{w}$

$\frac{\partial \theta_{i m}}{\partial t}=-S_{i m}+\Gamma_{w}$

The subscripts $\mathrm{m}$ and im refer to the mobile and immobile water regions, respectively; $\theta=\theta_{m}+\theta_{i m}$ and is the volumetric moisture content, $S_{i m}$ and $S_{m}$ are sink terms (root water uptake) for both regions $\left[\mathrm{T}^{-1}\right]$, and $\Gamma_{w}$ is the transfer rate for water exchange between macro-pores and matrix $\left[\mathrm{T}^{-1}\right]$. We assumed that root water uptake was preferentially from macro-pores, so that $S_{i m}=0$.

In the dual porosity flow model based on mass transfer driven by differences in soil water pressure head, the exchange rate of water between the macro-pores and matrix regions, $\Gamma_{w}$, was assumed to be proportional to the difference in pressure heads between the two pore regions (Gerke and van Genuchten 1993; Simunek et al. 2003):

$\Gamma_{w}=\omega\left(h_{m}-h_{i m}\right)$

Here, $\omega$ is a first-order mass transfer coefficient $\left(\mathrm{L}^{-1} \mathrm{~T}^{-1}\right)$. Since pressure heads are now needed for both regions, this approach requires estimating retention curves for both pore regions. That means each region has its own values of: $\theta_{r}, \theta_{s}, \alpha$, and $n$. As a result, soil hydraulic properties are now described by six parameters for macropores $\left(\theta_{r}, \theta_{s}, \alpha, n, K_{s}, l\right)$, four parameters for the matrix $\left(\theta_{r-i m}, \theta_{s-i m}, \alpha_{i m}, n_{i m}\right)$, and a parameter $(\omega)$ for mass transfer between the two zones (Simunek et al. 2003).

\section{Soil Hydraulic Properties}

Soil hydraulic parameters of both domains are described (van Genuchten 1980) using

$\theta=\theta_{r}+\left(\theta_{s}-\theta_{r}\right)\left(1+|\alpha h|^{n}\right)^{-m}$ 
$K\left(S_{e}\right)=K_{S} S_{e}^{0.5}\left(1-\left(1-S_{e}^{1 / m}\right)^{m}\right)^{2} ; \quad m=1-1 / n$

where: $\theta_{s}(-)$ is saturated and $\theta_{r}(-)$ residual water content parameter, $\alpha\left(L^{-1}\right), n(-)$, and $m(-)$ are empirical coefficients, $\mathrm{K}_{\mathrm{s}}$ is the value of $\mathrm{K}$ at water saturation, and $S_{e}=\left(\theta-\theta_{r}\right) /\left(\theta_{s}-\theta_{r}\right)$ is the reduced water content.

\section{Measured Hydraulic Parameters}

Because of the destructive method of soil block excavation, hydraulic parameters could not be determined directly for the analyzed 2D cross-section. Instead, mine soil water retention characteristics were measured using samples from a profile a few meters from the study site. In May 2012, 35 undisturbed soil cores $\left(100 \mathrm{~cm}^{3}\right)$ were sampled from depths of $5,15,25,40$, and $50 \mathrm{~cm}$. Water retention characteristics (Fig. 2) were determined using ceramic suction plates (Romano et al. 2002) in the suction range of $0-745 \mathrm{~cm}$ at 20 different pressure steps.

\section{Estimation of Hydraulic Parameters}

Hydraulic conductivity and the mine soil matrix water retention function were estimated using pedotransfer functions in which the parameters were calibrated for mine soil properties (Buczko et al. 2001). Here, available data from the Shenshan study site were utilized and the effect of lignitic fragments and particles on the hydraulic functions was considered. The pedotransfer function approach for the lignitic mine soil is based on the Arya-Paris-model (Arya and Paris 1981) for the water retention $[\psi(\theta)]$ function. For estimating $\psi(\theta)$, the Arya and Paris (1981) model was applied in a first step to the mineral fraction, $V_{s}(<2 \mathrm{~mm})$ (i.e. the 'fine' soil excluding $V_{s}(>2 \mathrm{~mm})$ of lignitic

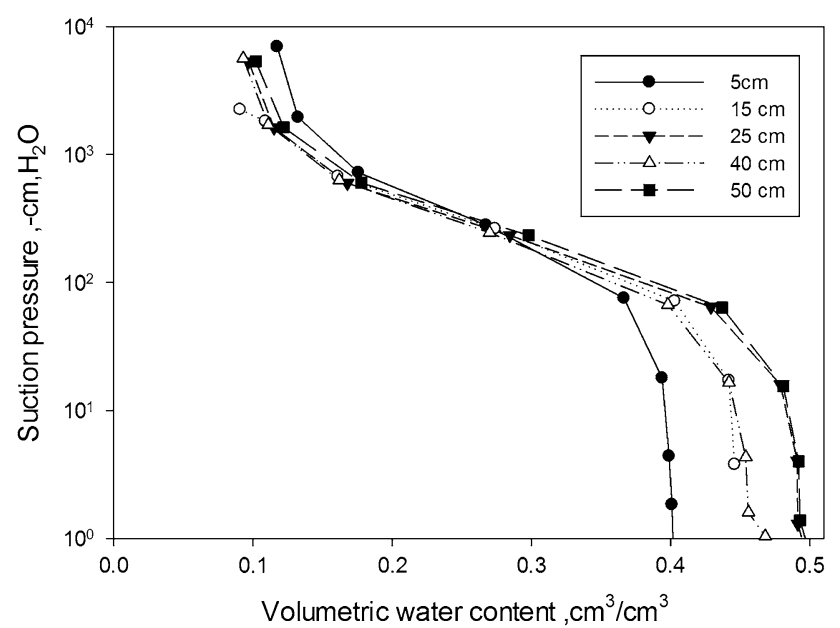

Fig. 2 Measured water retention characteristics at different soil depths fragments and gravel) of the spoil heap. The pore radius, $r_{i}[L]$, corresponding to the particle size class, $i$, is calculated as:

$r_{i}=R_{i}\left[\frac{2 \varepsilon}{3(1-\varepsilon)}\left(\frac{3 M_{i}}{4 \pi R_{i}^{3} \rho_{s}}\right)^{1-\alpha_{A P}}\right]^{1 / 2}$

with $R_{i}$, the mean radius of particles of particle size class $i[L], M_{i}$ is the mass fraction of particle size class $i, \rho_{s}$ is the density of particles $\left[\mathrm{ML}^{-3}\right]$, and $\alpha_{A P}$ is a scaling parameter (the subscript AP denotes Arya and Paris). The matrix potential, $\psi_{i}[L]$, is calculated from the pore radii using the capillary rise equation:

$\psi_{i}=-\left(\frac{2 \sigma \cos \beta}{\rho_{w} g r_{i}}\right)$

Here, $\sigma$ denotes surface tension of pore water $\left[\mathrm{MT}^{-2}\right], \beta$ is the wetting angle of the water menisci on the pore walls, and $\rho_{w}$ the density of water $\left[\mathrm{ML}^{-3}\right]$. The volumetric water contents, $\theta_{i}$ for the matrix potentials, $\psi_{i}$, and the drained pore sizes corresponding to the $i$ th particle size class are obtained by summing up the volumes of all pores, $V_{P, i}$, of the size class, $i$, as:

$\theta_{i}=\sum_{i} V_{P, i} \rho_{b}$

In a second step, the water retention curve for the lignitic particle (Fig. 3) was derived from the volumetricallyweighted difference between the mean measured water retention curve in Fig. 2 (i.e. $100 \%$ soil volume comprising both mineral particles and lignitic fragments) and the mean curve of the mineral soil matrix obtained with the Arya-Paris approach. It reflects the distinctly different pore size distribution and the much higher water retention

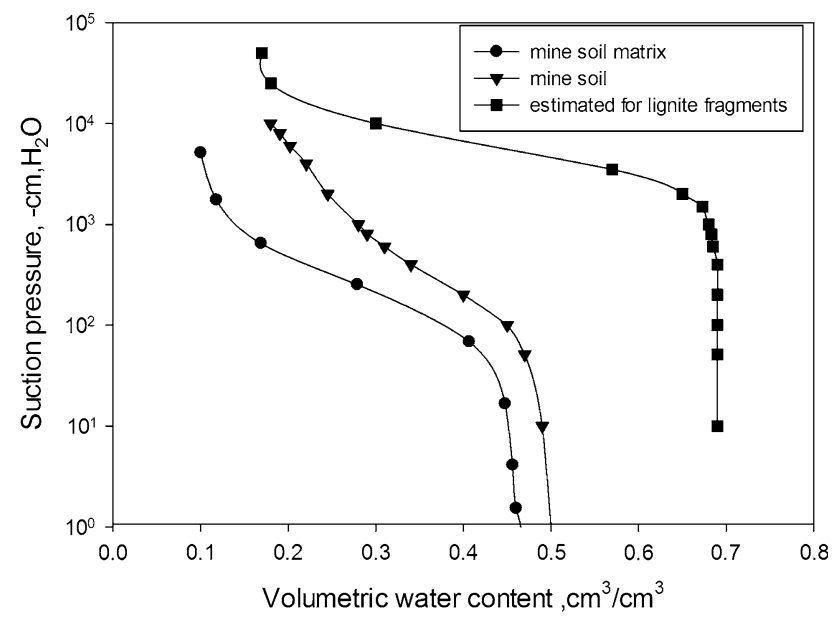

Fig. 3 Estimated water retention curve for lignitic fragments, mean measured data for the total soil, and Arya-Paris retention data predicted for the mineral soil matrix 
Table 1 Average values of soil properties at the monitoring depths

\begin{tabular}{|c|c|c|c|c|c|c|c|c|}
\hline \multirow{2}{*}{$\begin{array}{l}\text { Depth } \\
\text { (cm) }\end{array}$} & \multirow{2}{*}{$\begin{array}{l}\text { No. of } \\
\text { samples }\end{array}$} & \multicolumn{2}{|l|}{ Soil } & \multirow{2}{*}{$\begin{array}{l}\text { Textural } \\
\%(\mathrm{w} / \mathrm{w}) \\
20-10 \mu \mathrm{m}\end{array}$} & \multicolumn{2}{|l|}{ Fraction } & \multirow{2}{*}{$\begin{array}{l}\text { Bulk density } \\
\left(\mathrm{g} \mathrm{cm}^{-3}\right)\end{array}$} & \multirow{2}{*}{$\begin{array}{l}\text { Organic C } \\
\%(\mathrm{w} / \mathrm{w})\end{array}$} \\
\hline & & $>50 \mu \mathrm{m}$ & $50-20 \mu \mathrm{m}$ & & $10-2 \mu \mathrm{m}$ & $<2 \mu \mathrm{m}$ & & \\
\hline 5 & 7 & 31.02 & 23.09 & 18.49 & 12.63 & 14.76 & 1.58 & 2.73 \\
\hline 15 & 8 & 24.8 & 24.57 & 20.36 & 13.49 & 16.79 & 1.57 & 3.84 \\
\hline 25 & 7 & 29.06 & 23.3 & 18.45 & 12.32 & 16.86 & 1.47 & 4.08 \\
\hline 40 & 8 & 25.09 & 26.35 & 19.51 & 12.34 & 16.72 & 1.53 & 7.48 \\
\hline 50 & 5 & 24.73 & 24.89 & 20.06 & 12.89 & 17.44 & 1.36 & 3.01 \\
\hline 60 & 3 & 29.88 & 23.21 & 17.95 & 12.06 & 16.9 & 1.74 & 3.21 \\
\hline
\end{tabular}

capacity of the lignite fragments as compared to the mineral soil matrix.

In this paper, the saturated hydraulic conductivity, $K_{s}$ was estimated from a pedotransfer functions (PTFs) (Wosten 1997). Wosten (1997) presented a function for determining $K_{s}$, as follows:

$K_{s}=1.15741 \cdot 10^{-7} \exp (x)$

where $x$ for sandy soil is:

$x=9.5-1.471\left(B D^{2}\right)-0.688(\mathrm{Om})+0.0369\left(\mathrm{Om}^{2}\right)$

$$
-0.332 \ln (C S)
$$

and where BD is bulk density in $\mathrm{g} \mathrm{cm}^{-3}$, CS is the sum percentage of clay and silt, and $O_{m}$ is the percentage of organic matter.

The HYDRUS-1D model (Simunek et al. 2008) was used to simulate flow at the field site using hydraulic parameters obtained with PTFs. The HYDRUS-1D software (Simunek et al. 2008) was used to run the simulation. This software gives options to run simulation with the van Genuchten Eq. (4). The unsaturated hydraulic conductivity (K) function was calculated using Eq. (5) for the van Genuchten-Mualem model.

A separate simulation run was performed with HYDRUS-1D for each PTF. Water retention was estimated by applying the PTFs to the soil properties for each individual layer at the Shenshan field site (0-10, 10-20, 20-30, 30-50, and 50-70 cm; see Table 1).

\section{Results and Discussion}

Observed and simulated soil water contents are shown in Fig. 4. The topsoil $(5,15$, and $25 \mathrm{~cm})$ exhibited more weather-related variation in water content than the subsoil or mine soil $(40,50$, and $60 \mathrm{~cm})$, and the water content in the subsoil or mine soil $(40,50$, and $60 \mathrm{~cm})$ was greater than that of the topsoil. Figure 4 also shows that the mine soil water flow lagged behind initiation of rainfall. Yet in the second event, water flow responded very quickly to rainfall, which indicates that the mechanism of mine water

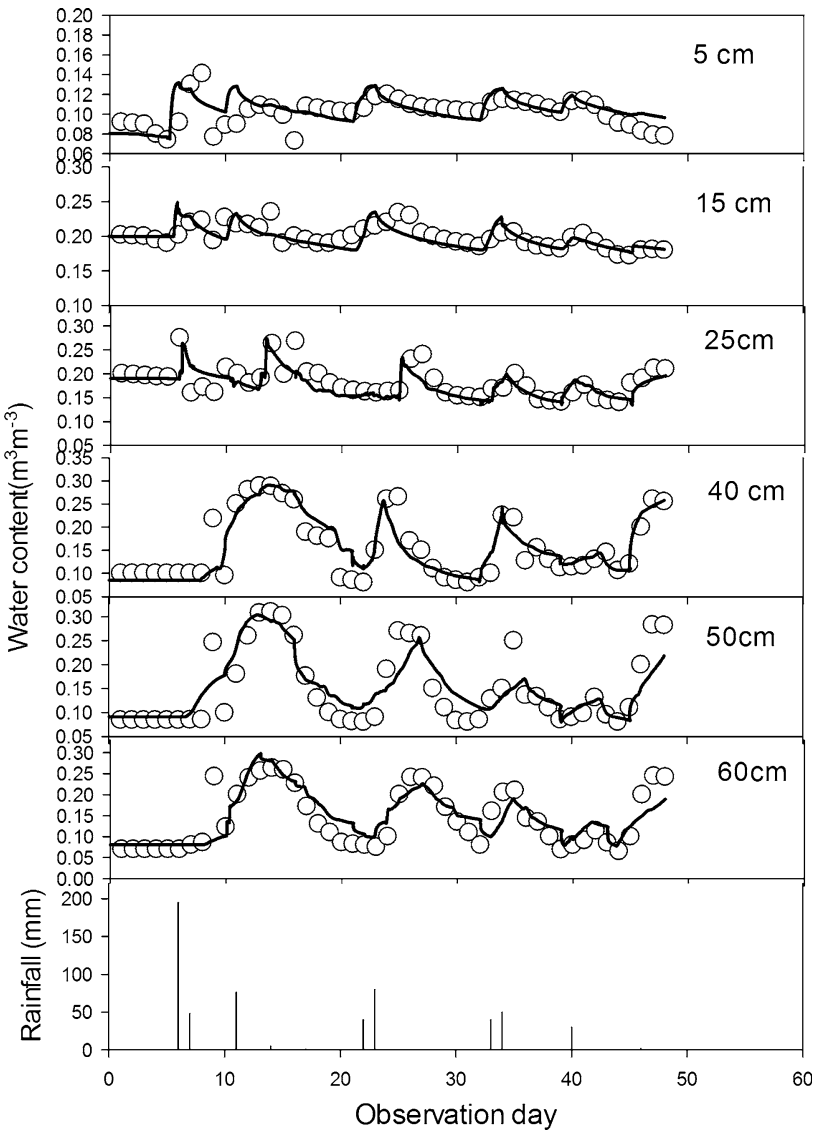

Fig. 4 Observed (symbols) and simulated (using the HYDRUS-1D model, lines) daily average water content; Observed values are averages across a transect for each depth and each day

flow must be dominated by rapid preferential flow through macro-pores in the mine soil rather than saturated flow through the mine soil matrix.

\section{Discussion of Flow Paths}

Still, it remains unclear how to explain how water in the lignitic fragments can be more mobile than in the matrix domain. The assumption that the lignitic fragments as a whole form a continuous pore domain would be difficult to 
verify. Nevertheless, the model analyses suggest the existence of non-equilibrium conditions and of a continuous pore system in which rapid water movement may take place. Observations show that the fragments itself can be heterogeneous and may not be homogeneously distributed; other observations indicate that a more continuous pore domain may be formed by lignitic components along surfaces of the fragments and smaller structures formed by lignitic in the mine soil matrix (Fig. 5). The integration of macro-pores in the mine soil horizon provides a mechanism for rapid downward movement of water through the unsaturated mine soil matrix.

In an attempt to verify the above formulated hypotheses on local flow paths in an unsaturated mine, we applied brilliant blue dye tracer in the waste dump of the Hei Dai Gou opencast coal mine, Ordos (Inner Mongolia, China). The Hei Dai Gou opencast coal mine is not at the same location as the Shenshan spoil heap, but they are only about $60 \mathrm{~km}$ apart. One liter of water containing Coomassie Brilliant Blue dye was slowly poured directly onto the surface of the mine soil. The dye readily penetrated into cracks surrounding surface fragments and into cracks beneath the fragments to an additional depth of $10 \mathrm{~cm}$. Where cracks were absent, the dyed water penetrated $<1 \mathrm{~mm}$ into the mine soil. The general vertical depth of penetration was $10-12 \mathrm{~cm}$. In general, dyed water tended to flow along narrow, discrete paths, the length of which depended on the abundance and proximity of coarse fragments.

Infiltration of dyed water into the macro-pores and subsequent excavation revealed preferential flow paths along macro-pores developed around and connecting coarse fragments within the mine soil matrix (see Fig. 5). The integration of surface and subsurface cracks into a

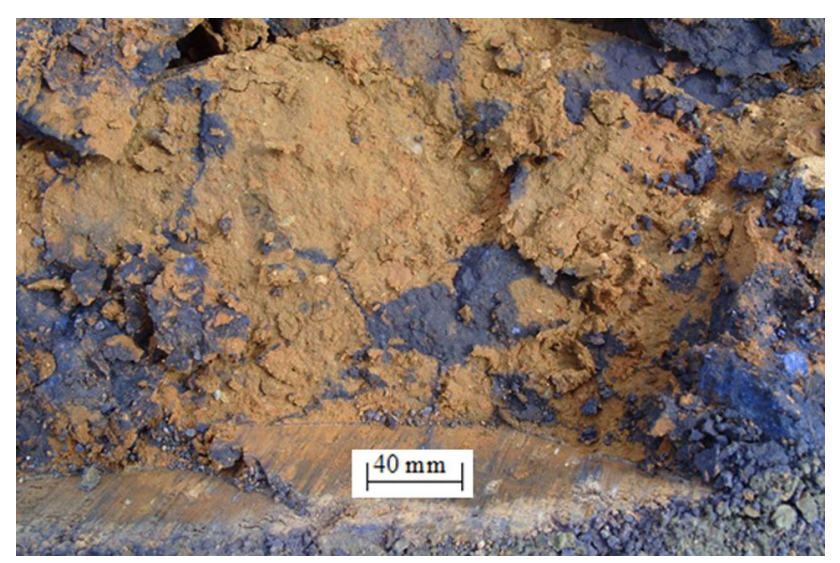

Fig. 5 Macropores in the mine soil of the Hei Dai Gou opencast coal mine dump site beneath coarse fragments that are embedded within a sandy mine soil matrix mine soil macro-pore network provides an important pathway for water flow to occur.

Most dyes consist of relatively large organic molecules and, as such, interact to some degree with the solid matrix in soils and aquifers. Dyes have the ability to stain the travel paths of water and solutes in soils and are thus useful for visualizing water flow patterns. In general, organic dyes have amphiphilic characteristics, i.e. the molecule has both hydrophobic and hydrophilic properties. In addition, the functional groups of organic dyes can protonate and deprotonate depending on $\mathrm{pH}$, thereby changing the net charge of the molecule. Because of these characteristics, interaction of the dye molecule with soil surfaces is rather complex. Sorption of dyes to solid surfaces involves one or a combination of the following interactions: hydrophobic, van der Waals, ion exchange, covalent bonding, and hydrogen bonding. The Coomassie Brilliant Blue dye is zwitterionic (amine and sulfonic acid groups) and has a solubility of $200 \mathrm{~kg} \mathrm{~m}^{-3}$. It is nontoxic and, depending on $\mathrm{pH}$, the dye is either neutral or dissociates to a mono- or bivalent anion (Flury and Flühler 1995). The Coomassie Brilliant Blue dye is a charged organic molecule that consists of polar and non-polar portions; sorption studies indicate that hydrophobic interactions are much less important than electrostatic or sorbate-mineral surface interactions (Flury and Flühler 1995; Ketelsen and MeyerWindel 1999). The non-conservative nature of the Coomassie Brilliant Blue tracer is probably enhanced by relative slow volumetric flow through the highly absorbent materials in the mine soil.

The $\mathrm{pH}$ of the solution determines the degree of dissociation of the sulfonic acid groups and directly influences the net charge of the dye molecule. At the low $\mathrm{pH}$ of the soil, the molecule is predominantly in its neutral form, and may be more prone to adsorption in soils than anionic species. Qualitatively, the data are consistent with the presumption of increased sorption at low $\mathrm{pH}$, although $\mathrm{pH}$ and soil texture can often interfere with sorption (Judit and Markus 2000). For tracing in field soils, a dye should preferably be mobile, distinctly visible, and nontoxic. The two criteria of visibility and mobility are to a certain degree mutually exclusive, because to stain the flow paths of water or solutes, the compound has to be retained. The advantages of Coomassie Brilliant Blue, especially for mine soil use, are its visibility against the color of the soil and its low toxicity. From the point of view of mobility, however, Coomassie Brilliant Blue is not ideal for tracing the travel times of water, but used in combination with conservative tracers, such as $\mathrm{Cl}^{-}$or $\mathrm{Br}^{-}$, Coomassie Brilliant Blue is useful for detecting flow patterns. We believe that, in terms of toxicity, visibility, and mobility, Brilliant Blue may be one of the best compromises available as a dye tracer in vadose zone hydrological studies. 


\section{Discussion of Model Concepts}

Figure 5 indicates that the network of flow paths within the mine soil follows a small-scale structure, especially connecting the interface regions surrounding lignitic fragments. A network of flow paths may develop where the fragments are close together and where, with the sandy matrix, large pores are bridged by lignitic particles or by slightly more compacted regions formed locally during the sedimentation process. Further assessment of flow in smallscale heterogeneous media was beyond the scope of this study.

\section{Summary and Conclusions}

We studied the effects of local heterogeneity (here in the form of embedded porous lignitic fragments) on observed preferential flow. Such lignitic mine soils represent a typical two-scale dual-porosity medium. The results were used to assess the most appropriate conceptual model for describing small-scale heterogeneity effects on flow. One hypothesis is that at the interface between the sandy matrix and the inner parts of lignitic fragments, a more conductive porous network exists. This 'interface' flow domain probably consists of the outer, more weathered and cracked regions of fragments and those sandy regions that have a higher lignitic content. The latter could be due to particle segregation and compaction within the spoil piles during sedimentation, which is one major difference between mine soils and naturally developed and aggregated soils.

This flow model fit reasonably well to the monitoring data (Fig. 4). Our attempts to use HYDRUS-1D (MIM) model simulations based on the Richards' equations were hence warranted.

Development of macro-pores, predominantly in the mine soil horizon, is the fundamental control on increases in infiltration rates following reclamation of surface-mined land. Macro-pores in the mine soil horizon provide a mechanism for rapid downward movement of water through the unsaturated mine soil matrix.

\footnotetext{
Acknowledgments We thank Ma Jin-line, vice-president of the Shenshan opencast coal mine, Ordos (Inner Mongolia, China), and Wang Ping-ling, vice-president of the Hei Dai Gou opencast coal mine, Ordos (Inner Mongolia, China) for their permission and cooperation in our conducting this work at those mines. We thank the National High Technology Research and Development Program 863 for funding this research.
}

Open Access This article is distributed under the terms of the Creative Commons Attribution License which permits any use, distribution, and reproduction in any medium, provided the original author(s) and the source are credited.

\section{References}

Arya LM, Paris JF (1981) A physic empirical model to predict the soil moisture characteristic from particle-size distribution and bulk density data. Soil Sci Soc Am J 45:1023-1030

Buczko U, Gerke HH (2005) Evaluation of the Arya-Paris model for estimating water retention characteristics of lignitic mine soils. Soil Sci 170(7):483-494

Buczko U, Gerke HH (2006) Modeling two-dimensional water flow and bromide transport in a heterogeneous lignitic mine soil. Vadose Zone J 5(1):14-26

Buczko U, Gerke HH, Huttl RF (2001) Spatial distribution of lignite mine spoil properties for simulating $2 \mathrm{D}$ variably saturated flow and transport. Ecol Eng 17:103-114

Flury M, Flühler H (1995) Tracer characteristics of Brilliant Blue FCF. Soil Sci Soc Am J 59:22-27

Gerke HH (2006a) Exploring preferential flow in forest-reclaimed lignitic mine soil. Adv Geoecol 38:380-387

Gerke HH (2006b) Preferential flow descriptions for structured soils. J Plant Nutr Soil Sci 169:382-400

Gerke HH, van Genuchten MT (1993) A dual-porosity model for simulating the preferential movement of water and solutes in structured porous media. Water Resour Res 29(2):305-319

Gerke HH, van Genuchten MT (1996) Macroscopic representation of structural geometry for simulating water and solute movement in dual-porosity media. Adv Water Resour 19(6):343-357

Gerke HH, Frind EO, Molson JW (1998) Modeling the effect of heterogeneity on acidification and solute leaching in overburden mine spoils. J Hydrol 209:166-185

Gerke HH, Molson JW, Frind EO (2001a) Modeling the impact of physical and chemical heterogeneity on solute leaching in pyretic overburden mine spoils. Ecol Eng 17(2-3):91-101

Gerke HH, Hangen E, Schaaf W, Huttl RF (2001b) Spatial variability of potential water repellency in a lignitic mine soil afforested with Pinus nigra. Geoderma 102:255-274

Hangen E, Gerke HH, Schaaf W, Huttl RF (2004) Flow path visualization at a lignitic mine soil using iodine-starch staining. Geoderma 120:121-135

Hangen E, Gerke HH, Schaaf W, Huttl RF (2005) Assessment of preferential flow processes in a forest-reclaimed lignitic mine soil by multicell sampling of drainage water and three tracers. J Hydrol 303(1-4):16-37

Jarvis NJ (2007) A review of non-equilibrium water flow and solute transport in soil macropores: principles, controlling factors and consequences for water quality. Eur J Soil Sci 58(3):523-546

Judit G-H, Markus F (2000) Sorption of Brilliant Blue FCF in soils as affected by $\mathrm{pH}$ and ionic strength. Geoderma 97:87-110

Ketelsen H, Meyer-Windel S (1999) Adsorption of Brilliant Blue FCF by soils. Geoderma 90:131-145

Romano N, Hopmans JW, Dane JH (2002) Suction table. In: Dane JH, Topp GC (eds) Methods of soil analysis, part 4, physical methods, 3.3.2.6, Soil Sciences Soc of America Book Series No 5, Soil Science Soc of America, Madison, WI, p 1692

Simunek J, van Genuchten MT (2008) Modeling nonequilibrium flow and transport processes using HYDRUS. Vadose Zone $\mathrm{J}$ 7(2):782-797

Simunek J, Wendroth O, Wypler N, van Genuchten MT (2001) Nonequilibrium water flow characterized from an upward infiltration experiment. Eur J Soil Sci 52(1):13-24

Simunek J, Jarvis NJ, van Genuchten MT, Gardenas A (2003) Review and comparison of models for describing non-equilibrium and preferential flow and transport in the vadose zone. J Hydrol 272:14-35

Simunek J, M Sejna, and MT van Genuchten (2008) The HYDRUS1D software package for simulating the one-dimensional 
movement of water, heat and multiple solutes in variablysaturated media. Version 4.0, Dept of Environmental Sciences, Univ of California Riverside, CA

van Genuchten MT (1980) A closed-form equation for predicting the hydraulic conductivity of unsaturated soils. Soil Sci Soc Am J 44:892-898
Wosten JHM (1997) Pedotransfer functions to evaluate soil quality. In: Gregorich EG, Carter MR (eds) Soil quality for crop production and ecosystem health, developments in soils science, vol 25. Elsesevier, Amesterdam, pp 221-245 